\title{
Containing the Anxieties of Children, Parents and Families from a Distance During the Coronavirus Pandemic
}

\author{
Jordan Bate ${ }^{1} \mathbb{D} \cdot$ Norka Malberg $^{2}$
}

Published online: 14 July 2020

○) Springer Science+Business Media, LLC, part of Springer Nature 2020

\begin{abstract}
The coronavirus pandemic and the move to teletherapy has created uncertainty among both clinicians and patients. As therapists who work with children, we have heard from parents who are desperate for support and advice about how to respond to their children's behavioral changes, as well as those who feel too overwhelmed to continue their children's sessions at the moment and want to take a break from treatment. We have had to rethink the frame in concrete ways, reimagine how to play, and renegotiate parameters around confidentiality. At a time when fear and uncertainty make mentalizing difficult, the hallmarks of a mentalizing approach—curiosity and flexibility—are most critical. This paper will describe how the Mentalization-Based Treatment for Children (MBT-C) model offers a framework for an integrative approach that can inform treatment via teletherapy, so that clinicians can continue supporting young people and their families through this period. We will begin by describing how the mentalizing stance, particularly an awareness of our own mentalizing capacities in the moment, has become more important than ever. Ways in which clinicians maintain their mentalizing in the face of the mentalizing breakdowns will be also discussed. Finally, we illustrate with clinical vignettes how the developmental levels of mentalizing — attention control, emotion regulation, and explicit mentalizing — can inform the structure, techniques and interventions in teletherapy with children and parents.
\end{abstract}

Keywords Mentalization $\cdot$ Child psychotherapy $\cdot$ Attachment theory $\cdot$ Teletherapy

\section{Introduction}

The coronavirus pandemic has elevated fears, anxieties and stress, and the precautions have isolated individuals and families. Measures have included closing schools and moving lessons online, resulting in millions of children being confined to their homes. This situation has created an enormous burden on parents to provide care, security and safety, while facilitating home schooling and balancing work and fears of their own. Hesse and Main (1999) remind us that "Whether or not attachment behavior is displayed at a given time, the young attached individual must at some level continually attend to the safety versus threat implicit in current conditions, while simultaneously monitoring the location

Jordan Bate

Jordan.bate@yu.edu

1 Ferkauf Graduate School of Psychology, Yeshiva University, 1165 Morris Park Avenue, Bronx, NY 10461, USA

2 Yale School of Medicine, Yale Child Study Center, $230 \mathrm{~S}$ Frontage Road, New Haven, CT 06519, USA and accessibility of those attachment figures upon whom its survival depends." (p. 494). While children monitor the location and state of mind of their caregivers, they and their parents also monitor the location and accessibility of their therapists.

A 2010 report from the National Commission on Children and Disasters stated the need to address the mental health and wellbeing of children and their parents during disasters, and this need has been backed up by research. A study on the experiences of parents and children during the $2009 \mathrm{H} 1 \mathrm{~N} 1$ pandemic in the United States, Mexico and Canada revealed that more than one third of children experienced clinically significant PTSD symptoms associated with social distancing and quarantines (Sprang and Silman 2013). Furthermore, parents' PTSD symptoms were positively correlated with their children's symptoms (Sprang and Silman 2013). In a correspondence recently published by The Lancet, titled, "Mitigate the effects of home confinement on children during the COVID-19 outbreak," Wang et al. (2020) echo the sentiments of Hesse and Main, "In the event of home confinement, parents are often the closest and best resource for 
children to seek help from. Close and open communication with children is the key to identifying any physical and psychological issues and to comforting children in prolonged isolation" (p. 946).

In the current situation, therapeutic approaches that can be adapted to teletherapy and also address the vulnerabilities currently facing families are much needed. Child therapists are exploring many questions about how to support families, engage with children over video, play when we are not physically together, involve parents, and keep the therapeutic frame (i.e. the consistency of time, a private space, and the therapeutic stance of technical neutrality and containment). An integrative theoretical model like the one provided in mentalization-based treatments can serve as a roadmap during this period of change for clinicians working across different orientations.

\section{Mentalization in Times of Crisis}

Mentalization, operationalized and measured in research studies as reflective functioning, is defined as the capacity to understand behaviors of yourself and others in terms of underlying thoughts, feelings and intentions (Allen et al. 2008). While it is a skill that we employ daily to navigate our social worlds, when we are exposed to traumatic stress, the ability to mentalize becomes even more critical to resilience. Mentalizing is a capacity that is context specific (Bateman and Fonagy 2016). We may be able to mentalize quite well at certain times or in certain relationships, but at other moments we can lose the capacity.

\section{Mentalizing and Emotional Arousal/Regulation}

One factor that plays an important role in mentalizing is emotional arousal and regulation (Fonagy and Bateman 2016). When emotional arousal is high, our mentalizing may become imbalanced or we may stop mentalizing entirely, which is adaptive from an evolutionary perspective. For example, if I am being physically threatened, it is not in my interest to explicitly consider the mind of the person attacking me or my own mental state, because I need to protect myself by running away or fighting back. The relationship between emotional arousal and mentalizing points to the complex link between mentalizing and the attachment system. The function of the attachment system is to respond to and manage distress through proximity seeking, and the capacity for mentalization develops in the context of early attachment relationships (Rothbart et al. 2011; Slade 2014). But when the distress is high, for example when one is feeling attacked or abandoned, then it becomes more difficult to mentalize.

\section{Developmental Modes of Pre-mentalizing}

Fonagy and Target (1996) identified three modes that they refer to as non-mentalizing or pre-mentalizing, because developmentally they are normative and precede the development of the full capacity to mentalize. These modes are labeled teleological, psychic equivalence, and pretend mode. When a person is mentalizing they are able to identify an internal experience that can be symbolically represented and seen as associated with external behavior. In contrast, non-mentalizing modes are characterized by variations in how internal "experiences" are linked to external "realities."

In teleological mode, there is no consideration of internal intentions or motivations, and internal states are only recognized through external physical "realities." For example, a child who only feels cared about by the therapist if allowed to take a toy home, or an adolescent who self-harms to relieve pain, are both in teleological modes. Internal experiences of the self or other are only considered to be real if they are visible or enacted in the external world. When patients are in teleological mode, the therapist often feels the urge or pressure to take action or do something.

In psychic equivalence mode, internal states are experienced as directly linked to external realities rather than as representations. For example, a child who gets accidentally hurt on the playground and is angry says that his friend "was definitely angry and meant to hurt him," or a parent who says about her daughter, "she won't eat anything I cook because she hates me." Beyond recognizing internal experiences in the self or the other, there is an assumption that what one thinks or feels must in fact be true. In moments like these, the therapist often notices in herself the desire to question or challenge what the patient is saying because it sounds extreme or distorted.

Finally, pretend mode is a state in which the child or parent can consider internal experiences, but only when they are completely separate from external realities. The healthy and adaptive end of this spectrum is when children engage in fantasy play. But in pretend mode, rather than representing thoughts, feelings and experiences that are connected with the external world, the child's play can feel like it is happening in a bubble, containing little meaning. In adults, pretend mode can be observed when parents use intellectualizing defenses and psychological jargon that is disconnected from any affect. The clinician may notice in themselves feelings of boredom or emptiness, or a feeling of compliance with what appears to be pseudo-mentalizing or an "as-if" state.

We describe these non-mentalizing modes in detail because in our view they have become increasingly 
prevalent in the face of the COVID19 pandemic, not only among children and parents, but also among clinicians. The effects of the coronavirus pandemic are at both global and individual levels. Clinicians are not immune from worries about their own health or the health of loved ones, social isolation and grief about quarantines, anxiety about the financial situation, anger about hospital conditions, or fear and uncertainty in the face of an invisible virus. It is therefore critical that clinicians be aware of the potential for breakdowns in our own mentalizing, which are more likely to occur when our anxieties and helplessness are stirred up, as they often are these days. Seeing our patients via telehealth is simultaneously an opportunity for us to feel productive and find meaning and connection with our patients, while also reminding us what we are missing and how not-normal things are. This set of conditions exacerbates the challenge to retain the capacity to think and self-observe emotionally whilst adjusting the therapeutic frame to the emerging and changing needs of children, adolescents, and caregivers.

\section{Time-Limited Mentalization-Based Approach for Children and Parents (MBT-C)}

The following sections of this paper will describe how a time-limited mentalization-based approach for children and parents (MBT-C; Midgley et al. 2017) can provide a framework for modifying our techniques and the therapeutic stance in teletherapy with children and parents in this unique time, while taking into account our own states of mind as clinicians. We hope to illustrate one of the basic premises of mentalization-based interventions, which is the value of focusing on the process and not the content of the therapeutic encounter. We will enumerate three elements highlighted in the MBT approach, which can promote and facilitate the transition from in-person intervention to remote ways of interacting with children and families therapeutically:

(1) The value of a mentalizing stance based on creativity, flexibility and genuine curiosity (Bleiberg 2013).

(2) The necessity of meeting children and parents "where they are" with MBT-C's three mentalizing building blocks, which provide a clear, developmentally appropriate holding framework to guide and contain the clinician's anxiety around modification of therapeutic stance and overall technique (Midgley et al. 2017).

(3) The need to approach our work with parents and children from a not-knowing stance, keeping in mind the information we have about dyad's relational pasts and how it might be impinging on the parent's capacity to mentalize their child's emotional experience during this time of crisis.

\section{The Value of a Mentalizing Stance}

Slade (2008) reminds us that in our work with parents, "reasoned flexibility" is of the utmost importance. In the context of child psychotherapy, it is not always possible to hold a pure approach with a fixed, predetermined structure. During moments of external crisis, a conscious awareness of the mentalizing stance serves as a baseline, particularly in the current climate of the pandemic. We are seeking to re-engage with families and children from afar while we are also depending on our pre-existing internal ways of coping in facing an invisible, external enemy. A mentalizing stance tends to be characterized by the following elements: (1) playfulness and appropriate use of humor; (2) the explicit effort to tease out mental states underlying behavior; (3) recognizing developmental aspects of mental states; and (4) an awareness of the opaqueness of mental states, that is, that they can never be fully known either by the person themselves or by another person (Allen et al. 2008).

Overall, this approach is one of openness to new experiences in the therapeutic encounter, which are received and responded to verbally and non-verbally, in an explicit, nonjudgmental and curious way. The main aim of MBT-C during periods of toxic stress, like the one we are experiencing right now, is to model an interpersonal stance that fosters mentalizing, and with it, containment and regulation of emotions triggered by the collective experience of threat.

Regarding this matter, Berthelot et al. (2015) have demonstrated the significance of trauma-specific reflective functioning. Their findings show that parents' trauma-specific reflective functioning, but not reflective functioning in general, significantly added to the variance in disorganized attachment that was already explained by parents' unresolved states of mind. Research on the impact of chronic illness and mentalization with adolescents (Malberg et al. 2008) similarly showed that once the experience of illness is able to be thought about with the support of parents and medical personnel from a curious and accepting stance, medical adherence improves. However, individual differences were observed depending on the young person's personality and overall socio-emotional functioning prior to the onset of illness. Finally, in younger children, 3-8 years old, who experienced sexual abuse, the relationship between sexual abuse and reflective functioning (specifically with regard to others) three years later was mediated by difficulties developing and concluding the stories in their play at baseline (Tessier et al. 2016). Such findings suggest that scaffolding symbolic play to help children elaborate and conclude their narratives may offer one pathway to restoring mentalizing after a trauma.

The mentalizing stance is particularly valuable as we make the shift to teletherapy. We have noticed in ourselves 
and our colleagues a desire to have answers for our patients and clear plans for the structure of sessions. Such urges are an indication that as a system we may be in a teleological mode, focused on what to do and taking action rather than tolerating the uncertainty and relying on the creativity and playfulness that we employ on a regular basis with our patients. In MBT-C, when we notice that either we ourselves or the families we are working with are operating from a non-mentalizing stance, we implement interventions specifically aimed to interrupt non-mentalizing and restore mentalizing. We recognize that people stop mentalizing when affective arousal is high, and therefore begin with interventions that are containing and supportive, rather than interpretive.

A key tool for beginning teletherapy with children and parents is "noticing and naming." For many of us, this is the first time we are seeing our patients through a screen. It is also the first time we are connecting with them while in separate places, and of course the first time we are experiencing a pandemic. We may attempt to create structure, for example, by suggesting that the child choose a place in the home for us to sit together. However, we openly acknowledge that this setting is not the same; in fact, it is very, very different. We have never interacted through a screen with each other from separate places, and we are going to have to learn to do this together.

The mentalizing stance enables the screen to become a new container and space for co-construction with both children and families. Over the last couple of decades, the work of child therapists like the Novicks (2005) has promoted the more explicit inclusion of parents in the work with children and adolescents. The COVID-19 pandemic does not just effect individuals, but also effects systems, including the family system. In some cases, the pandemic has highlighted or made worse conflicts that already existed in the family, and in other cases it has exposed new challenges. The mentalization-based framework allows us to explore patterns on both individual and family systems levels. We often do this first with children and adolescents, and then help to generate conversations and interactions that will raise the mentalizing capacities of other members of the family. We have found that teletherapy has made it somewhat easier to engage these other members of the family in the therapeutic work because they are all at home together. The following vignette is an example of such an occurrence.

Adam, age 15, has been in once weekly psychotherapy for three years due to difficulties connecting with peers. Both home and school reported unexpected emotional outbursts consisting of floods of tears and aggressive verbal discourse. From an MBT perspective, Adam falls into psychic equivalence modes of functioning when he perceives others as critical or mocking. Despite multiple interventions throughout the years, Adam struggles with a "mind blindness" characteristic of young people in the autistic spectrum. Two years ago, Adam had declined his therapist's invitation to meet online during a period in which his therapist would be away, so they had never tried online interactions. Adam felt it was "just not the same, it makes me too nervous." Much to his therapist's surprise, after sending an email invitation to Adam he requested an appointment via Zoom. The following is the narrative offered by Adam's therapist about their first session online:

At first, I could sense my own uneasiness as he refused to look at the screen. When I mentioned this, Adam said it was weird to see himself. I explained there was a way in which he could see me if he wished to, but he did not have to see himself. He opted for this option during the first session. At first, Adam's voice was monotone as he described without much affect the recent events and the changes in the routine. A silence ensued, and I could see a familiar change in Adam's face. I said I could see the "longing, lonely look coming upon us," a description we had developed together in our work. Suddenly, Adam turned on his camera and stared at it, "That is how it looks! My mom hates it, she gets so angry and tells me to change my face." Together we were able to speak about how he imagined it made his mom feel and he said he had no words. He shared his screen and showed me a picture he had taken of his mom last time she was angry at him for looking "whiny." I asked what he thought my face was saying. He asked me if this was a game or serious, I said I thought a game was easier, "No worries about failing." He smiled.

I said I was really nervous about not knowing how to understand what he was feeling being so far away. He said sometimes he thought I was annoyed at him like his mom. I wondered if today was one of those times, but he said he did not think so. The end of the session was dedicated to a fight he had with his family prior to our session, in which he felt ignored and mistreated. He asked if his mom could come in and we could talk about it. I thought that was a good idea. Mom was in the next room and came in after Adam texted her. She explained that she was really upset because of all of the older people dying and her mom living alone so far away. Adam said that had nothing to do with how mean she and his brother had just been to him. Mom's face looked annoyed and I directed Adam's attention to it, "Adam what do you think is happening to mom?" "She is annoyed because I am selfish and I don't care," he said. I queried, "I am not so sure...mom, is that so?" Mom said it was not, but she could see how Adam thought that, 
"since everybody is in a bad mood, stuck at home and worried." Adam replied, "This is not the coronavirus thing, this is always like this..."

I found myself surprised and proud of his intervention, and added, “Adam, I think based on your mom's face and my feeling, I have to tell you that I think that what you just said is really important." Adam looked confused. I continued, "I think you are saying that this is a very stressful time for all of us, but the way you feel ignored by your family is not that different. Am I right?" A smiling Adam replied, "You got it!" Adam's mom smiled and acknowledged, "Sometimes we forget you are 15. For us you are still the baby of the family and that is not fair...."

This vignette illustrates how the therapist's curious and flexible approach invites Adam to "notice" both what is different now and also what is still the same, in terms of already existing patterns of interactions. By focusing on the current situation in a genuine and playful manner Adam is able to speak about a dysregulating interpersonal event. Interestingly, his mother gives a pretend mode response by associating the event to the stress of the coronavirus pandemic. Much to the therapist's surprise, and we suspect that of his mother, Adam helps his mom move away from a pretend mode of functioning and brings it to the here-and-now of an ongoing relational pattern that makes him feel alone and very sad.

In this case, the therapeutic alliance held patient and therapist together in a psychical room of sorts. Furthermore, by noticing his affective shifts explicitly and also being selfaware of her own facial expression and other non-verbal communications in the online session, the therapist attempted to reinforce an environment where trust facilitated thinking and social learning within a different container. For young people of Adam's age computers have multiple meanings. In Adam's case, looking at his image whilst in relation felt confusing, however, he discovered it was like looking in the mirror with someone standing next to him, allowing him to safely explore what the outside might be saying about the inside.

In summary, the mentalizing stance models behaviors and attitudes that foster the emergence of reflective functioning in both caregivers and children, and also provides the emergence of safety and epistemic trust even at a distance. Our bodies might not be present but our capacity to connect and explicitly and implicitly promote internal safety through relationships is an evolutionary capacity and a developmental imperative that is still very much with us.
MBT-C's Three Mentalizing Building Blocks

Although we have just argued for a flexible and open stance, the MBT-C model also values structure and scaffolding, especially to provide containment in which exploration can continue safely. MBT-C expands on the original MBT framework with more overt attention to the developmental process by outlining three building blocks of mentalizing: attention control, emotion regulation, and explicit mentalizing (Midgley et al. 2017). Though our goal is explicit mentalizing, a child in a full-blown tantrum, for example, will not be able to think about why his sister might not want to share with him right now. These building blocks are the internal and interpersonal skills that are needed in order to reach that point. The techniques that are associated with each block are often more active than interventions in a psychodynamic or psychoanalytic treatment but provide scaffolding for later exploratory work.

\section{Attention Control}

As described above, at least some degree of emotion regulation is required in order to be able to mentalize, though mentalizing also aids in emotion regulation. But prior to the development of emotion regulation there is first the ability to regulate attention. We do not often discuss attention regulation or control in the context of therapy, though it has been written about by attachment researchers like Mary Main (1996), as well as the parent-infant "baby watchers" like Beatrice Beebe (2005). Attention control is most obviously present in joint attention and when we are engaged in a shared activity with a patient. In MBT-C we are attuned to indications that the child does not have attentional control. We may observe that a child's attention is all over the place and they are hyperactive, or on the more subtle end of the spectrum, they may be hypervigilant or hyper-focused and not able to pull themselves away from something. When we notice these cues, we begin our work by attempting to re-engage the child in regulating their attention. Techniques for attention control include noticing and naming what is happening in the here and now, described above, as well as creating moments for joint attention, which can be done either by actively introducing or co-constructing an activity, or joining with the child and matching their verbal and nonverbal rhythms. In his 2003 paper, "Treating children who do not play or talk," Bonovitz vividly describes how he engages with a child who is withdrawn and nonverbal by scratching the couch in a way that both mirrors and responds to the way the child is scratching it, giving a sense of them creating music together or conversing through scratching. 


\section{Emotion Regulation}

As with attention control, we consistently attend to breakdowns in emotion regulation. Dysregulation is most commonly used to describe a child who becomes over-aroused and acts out, but in MBT-C we also pay attention to overregulation, where a child is tightly controlled and holding everything. At the more extreme end of the spectrum, the child's emotions may even appear shut off and flat affects predominate. Emotion regulating techniques in MBT-C aim to maintain an optimal level of emotional arousal and regulation.

Marked mirroring and empathic validation are key components of enhancing emotion regulation in psychotherapy. Marked mirroring (Fonagy et al. 2002) is a specific form of empathic validation that refers to the capacity of the therapist to show the child verbally and nonverbally that she is trying to understand and interpret the child's signals and expressions of emotion. Importantly, the therapist is not only attempting to provide an attuned and congruent response, but also communicating to the child that this expression being reflected back belongs to the child's internal world. In other words, it is the child's subjective experience that the therapist is attempting to represent, not her own feelings. Through repeated marked mirroring, the child begins to experience a sense of ownership and selfhood.

This element of the theory illustrates the integration of neuroscience, infant research and developmental and clinical theory. The mirror-neuron system (Gallese 2007), which registers actions and displays of affect when they are observed in another and is thought to contribute to humans' capacities for empathy, potentially also underlies the modulation of infant distress in dyadic interactions (Fonagy et al. 2007). Beebe et al.'s (2010) research has supported this theory, demonstrating that mothers help infants to regulate their distress by "joining" the infant's distress through marked mirroring, usually reflecting increasingly lower levels of affect. This integration of theory and research lends itself as a valuable source of technical reference for our work online with children and adolescents.

Other emotion regulation techniques include identifying "bumpy roads," being curious about perceptions and feelings, and introducing sensory materials and toys to help children regulate their emotions during more affectively charged situations and discussions. We also "play" with emotion regulation during the session, by watching and attending closely to escalating emotions and practicing "turning the volume up or down." When working online, these activities can be elicited by drumming together, looking at music videos online, or by making a competition of who can stretch a piece of clay the longest. Allowing the child to teach us about what he/she has available at home is also a great opportunity to create new "regulating routines" in vivo.

\section{Explicit Mentalizing}

Once children's attention and emotion are regulated, then we have the foundations for engaging in explicit mentalizing interventions. Such explicit mentalizing interventions include linking mental states to behaviors, playing with different perspectives, noticing breakdowns in mentalizing and intervening to restore it, and mentalizing the therapeutic relationship. Mentalizing the therapeutic relationship represents the highest level of mentalizing and is often the most challenging because is the most interpersonally stimulating. Mentalizing the relationship requires processing how our perceptions, internal experiences, and behaviors are impacting each other in the therapeutic relationship.

We have found the building blocks framework to be particularly valuable in teletherapy. Treatment in MBT-C begins with a thorough assessment of where the child and parent are in terms of these building blocks, but there also is an ongoing, implicit assessment of where the child (or parent) is at in any given session or at any given moment, in terms of their attentional control, emotion regulation and explicit mentalizing. In some sessions, we may move from one level to another and back-and-forth throughout, while in other sessions we may find ourselves working consistently at one level. All levels are considered therapeutic in their own right.

As MBT-C clinicians delivering teletherapy, we are tracking closely which levels we are at with our patients, and not expecting to be at the same level we were prior to this crisis. Furthermore, although there is an appreciation for following the child's lead, the model supports active interventions on the therapist's part, which are helpful in adapting to the online formats. The following description of a session illustrates how the clinician's awareness of these three levels can inform the approach and techniques that are specific to an online format:

The screen opens like the curtain to an unexpected play, and a 7-year-old toothless smile greets me. A shirtless Danny appears. I can hear his mother's voice in the back and see the silhouette of his grandmother in the horizon while she pets the family dog, the infamous "Toot," a 10-lb chihuahua. I know all the characters of this play, as they have visited me and Danny through stories while playing in the sandbox or the doll's house. They have also made occasional appearances in my waiting room for the last two and a half years. I have not seen Danny in three weeks, so he greets me with excitement and proceeds to show me where his mom sits to work, where his sister does her homework and where he plays with soldiers. I comment on the formation being very similar to the one we often set up in my consulting room and he agrees. We engage in a conversation about the strategy he is 
using, and I suddenly interrupt: "You know, I just realized how confused I feel." Danny stops in his tracks and makes a face. I continue, "We are talking about the game we play when we meet in my office, but now we are playing it in your room!" Danny laughs and tells me that we have to because there is a new enemy and his name is Mr. Corona. I ask him to tell me more. $\mathrm{He}$ sits on his bed and tells me with great detail that there is an illness that came from China which is hurting lots of people, so they have built a family bunker, and nobody can come in, not the invisible monster, Corona, nor the outsiders. I say, it is indeed a scary time, but Danny and his family seem to be keeping each other safe. Danny begins to move with the phone in his hand and the connection gets broken. Suddenly, I find myself speaking to Danny's mom who tells me all about the family's current functioning. She tells me she now understands how much work the teachers have to do to keep Danny calm. Perhaps, she says, she has been unfair with the teachers a bit.

I feel a bit frustrated myself, but I also understand that Danny has handed over the phone to mom for help. After a few minutes, I say, "Where is Danny? Did he disappear?" in a playful tone that is familiar to both mother and child. Mom smiles and tells me it has been nice to see me and that she might call to have a parent support session, I say that would be fine. In fact, most of my sessions with Danny's mom have been online due to her long working hours and her need to take care of her mother who lives with them.

Danny's dad works in the hospital as a nurse, so Danny appears on camera again wearing his dad's uniform. "I wonder what is going on, is this Danny or his dad?" I joke. Danny laughs loudly, "No, my dad is in the hospital fighting the good fight against the Corona monster." I tell Danny that I notice he is moving a lot; I wonder if thinking about the Corona monster makes him nervous. He says, "No silly! I am brave!"

We still have 15 minutes of our scheduled session and I wonder what Danny has been doing instead of going on recess. He tells me he has been watching a really cool show on YouTube. "You want to see it? I get to see 15 minutes when I do my reading..." I find myself wondering what to do, and I remember that such a thing is possible with the platform I am using. I ask Danny if he knows how to do it and in less than twominutes we are watching a clip from the show. Interestingly, the clip shows a kangaroo who wants to drive a truck, but they show us all the catastrophic things that can happen if it does. "That is one crazy video" Danny says. "Yes... she really wants to do something that is fun and exciting, but she can't because she could get hurt...!" I say. Though I am uncertain that my patient can work at this symbolic level and aware that we are miles apart, so I cannot offer the usual ways of containment (sand box, sensory toys or simply my physical presence), I nevertheless continue. "Danny, Danny..." he looks at me as his body collapses in the chair where he was seated earlier, "What ?!" he replies. "It's like us, we can't meet in person, we can't go to work or school, play with friends in the street...we are like the Kangaroo..." Danny relaxes and gives me a big toothless smile, "Don't worry, my dad will protect us." An affective shift occurs as we have five minutes left, Danny looks somber and somewhat concerned. He says he is bored now and hands the phone back to mom who tells him to say goodbye to me. I say, "Danny has been so great today to adapt to something we usually don't do." I can hear Danny reminding me that we have met online before, which is true, once when he was sick and on a couple of occasions when I was travelling. In fact, most children in my practice have had the experience of meeting with me online before, but this time is different. This time, we are both worried and scared about one common enemy, the Corona monster. Danny takes the phone back and asks when we will meet again, and I say next week at the same time.

Danny's case illustrates the value of an existing therapeutic alliance with the child and his caregivers. Danny begins by wanting to be close, he shows his therapist he has lost some teeth, thus marking the passage of time and the absence we have experienced from each other. As the session progresses, the therapeutic dyad navigates the daily functioning of his home guided by their existing patterns of interaction. He shows his therapist how he has managed to keep her present by setting up the battle ground. Parallel to the familiar interaction, though, there is the acknowledgement of the "invisible enemy," which emerges as a new organizing metaphor. The session goes from naming and noticing and the co-creation of new patterns of interaction to the explicit representation of the battle within Danny, his family and myself. As the new third—the technology—makes its voice heard, Danny's mom claims a bit of her own need for refueling and a seamless bridge gets created between the therapeutic space and the reality in Danny's home. With this bridge, we can enter into symbolic work, putting our experiences of being apart and confined into words. Danny is able to remind me and his mom that there is a past and a present and that he is holding both in mind. In an act of naming and noticing, likely in response to the regulating comments that had been made earlier, he is able to pick up the phone and assure me and, most importantly, himself that we will be able to survive this battle.

From an MBT-C perspective, the therapist and child navigate the three blocks of mentalizing in this session to 
facilitate the containment required to explore the impact of the external threat on Danny's already anxious functioning. Regulation was achieved by strengthening his capacity to mentalize his anxiety, with the support of both his internal and external objects. Later on, Danny's mother reported a plethora of Corona monster drawings but a much more collaborative Danny during home schooling time.

\section{Embracing Not-Knowing}

We are seeing the pandemic affect our patients in multiple ways. Some openly discuss their thoughts and feelings and cannot focus on anything else, others report somatic complaints, and still others have shored up their defenses by avoiding the news and picking up new hobbies at home. Children's anxieties are also presenting in varied ways. The emergence of regressive behaviors tends to be the most alarming to parents, who are already overwhelmed and isolated, and also deprived of the in-person connection with us that they are used to having weekly. Many parents have been vocal about their own needs and problems, and expressed difficulty managing their children's challenging behaviors and determining how to meet school requirements. Yet, for many parents who had not been able to engage before, working remotely has also made collateral parent sessions more accessible.

Integrating different theoretical orientations has proved helpful and even necessary during the COVID-19 pandemic to meet the needs of children and parents, and MBT-C offers a framework for bringing together cognitive, behavioral, emotion-focused, and exploratory approaches. Because mentalization is ultimately about appreciating the links between thoughts, feelings and behavior, the MBT-C model offers multiple ports of entry for our therapeutic work. We may work with parents or children. We can choose to intervene at the level of behaviors and interpersonal interactions, affect and cognitions, or the intrapsychic world of internal working models, which include psychodynamic conflicts and selfother representations (Stricker and Gold 1996). However, we consistently keep in mind the non-mentalizing modes, particularly teleological mode. We look out for when our focus becomes solely on how parents might respond to their children's behaviors, and we have lost sight of the parent's and the child's internal experiences in the present, which are also influenced by their pasts.

For children in foster care or who have histories of early relational trauma, for example, this is not the first time that they are facing fears about something happening to their caregivers. Their lives have often been characterized by uncertainty and a sense of social isolation. Understanding the impact of coronavirus and the move to online therapy in terms of the parallels with other aspects of the child's narrative is of great importance. Changing settings, whether it be homes or offices, requires some degree of re-learning ostensive cues and how to exist in a new territory, contextually and relationally.

The caregiver's state of mind must be attended to in this process. We need to hold parents through this time, so that they can hold their children. When we show an interest in and reflect with parents about their own experiences in this crisis, we are indicating that we see them as having agency and intentionality, and this increases their sense of trust in us, as well as their own sense of efficacy as parents. This rise in trust opens up what Fonagy and Allison (2014) call the "epistemic superhighway," where knowledge can be taken in. We find then that parents not only look to us for advice but are also free to think with us about ways of responding to their children's challenging behaviors while being empathic, containing and reassuring. All vignettes in this paper demonstrate that especially now, children need to know that the grownups in their lives-the bigger people-are able to tolerate hearing their feelings, from fear to sadness to frustration. And in order to help parents do this for their children, we need to show them that we can tolerate not just their child's feelings and behaviors, but also hearing about their experiences in all of this.

\section{Conclusions}

Threat is the number one enemy of mentalizing, whether it is perceived or real. A situation like the one we are experiencing at present requires a necessary movement from teleological, psychic equivalence and pretend modes of functioning towards a mentalizing and collaborative stance (Slade 2014). A mentalization-based focus aids the clinician in moving away from internalized expectations of what constitutes the therapeutic frame and allows us to adapt to this new reality.

In any orientation of child psychotherapy, the most important tool is the therapist's capacity to formulate and reformulate as the process of psychotherapy rapidly shifts and transforms. Expectations often weigh heavily on us. Like children, the field of child psychotherapy has often been the victim of child-ism. We tend to question ourselves and the value and impact of our work more than adult psychotherapists do, and this has been especially true in the move to remote therapy. This situation is a time for integration and for valuing what we can offer children and families; namely, containment, our capacity to think while under duress, and our ability to put words to the aspects of their experiences that feel too scary to be spoken about. We hope to have illustrated a clear framework based on the importance of relationships, which draws on robust research findings, and can hold the mind of the clinician at a time when all of our thinking is constrained by the presence of imminent threat. 
We encourage clinicians to make note of where children and parents are in each session using the building blocks of mentalization (attention control, emotion regulation, explicit mentalizing). It should be expected that during this particularly stressful period our interventions may need to focus more on establishing attention control and enhancing emotion regulation rather than promoting explicit mentalizing. It is tempting to feel as though everything has changed, but we also want to remind and reassure clinicians of our existing capacities for creativity and play. Though we are not in the same room and do not have the same toys, we can find elements of the therapy room in these new spaces to help us remain connected to the work there and each other. As with parents and infants, our faces, often the only part of us visible on the screen, are powerful therapeutic, communicative and expressive tools. And for patients we have been working with, we can also trust the relational patterns we have already established and maintain these rhythms even through the screen.

In order for us to do this work with children and families it is imperative that we attend to our own attachment systems and monitor our own mentalizing capacities in an ongoing way, so that we stop and interrupt vicious cycles of non-mentalizing that are at risk of emerging during crises. We cannot provide our patients with a sense of safety and reassurance if we are not able to contain our own anxieties. We intend for this article to assist with that containment, by providing a theoretical structure and viewpoint from which we can re-establish contact with ourselves and our patients. Containing anxieties does not mean not being anxious. Instead, it means being able to acknowledge anxiety, fear, uncertainty and deprivation in ourselves and others around us, and having the capacity to tolerate those emotions so that we can help our young patients to metabolize them and feel less alone.

During these uncertain times, modifying our therapeutic goals as well as trying to keep a sense of predictability amidst the chaotic uncertainty is of upmost importance. We hope to have illustrated that recruiting and informing parents of the changes in the process, as well as supporting them in self observing to identify the triggers for the loss of their reflective functioning is very important. All these considerations have one single goal, that of providing a holding and safe environment to all involved, including the mental health provider in times of uncertainty and fear.

\section{Compliance with Ethical Standards}

Conflict of interest The authors declare that they have no conflict of interest.

Ethical Approval Our work was conducted in accordance with the ethical standards of the American Psychological Association.

\section{References}

Allen, J. G., Fonagy, P., \& Bateman, A. W. (2008). Mentalizing in clinical practice. Arlington, VA: American Psychiatric Publishing.

Bateman, A. W., \& Fonagy, P. (2016). Mentalization based treatment for personality disorders: A practical guide. Oxford, England: Oxford University Press.

Beebe, B. (2005). Mother-Infant Research informs mother-infant treatment. Psychoanalytic Study of the Child, 60, 7-46.

Beebe, B., Jaffe, J., Markese, S., Buck, K., Chen, H., Cohen, P., et al. (2010). The origins of 12-month attachment: A microanalysis of 4-month mother-infant interaction. Attachment \& Human Development, 12(1-2), 3-141.

Berthelot, N., Ensink, K., Bernazzani, O., Normadin, L., Luyten, P., \& Fonagy, P. (2015). Intergenerational transmission of attachment in abused and neglected mothers: The role of trauma-specific reflective functioning. Infant Mental Health Journal, 36, 200-212.

Bleiberg, E. (2013). Mentalizing based treatment with adolescents and families. Child and Adolescent Psychiatric Clinics of North America, 22, 295-330.

Bonovitz, C. (2003). Treating children who do not play or talk: Finding a pathway to intersubjectivity relatedness. Psychoanalytic Psychology, 20(2), 315-328.

Ensink, K., Bertlelot, N., Bernazani, O., Normandin, L., \& Fonagy, P. (2014). Another step closer to measuring the ghosts in the nursery: Preliminary Validation of the Trauma Reflective Functioning Scale. Frontiers in Psychology, 5, 1471.

Fonagy, P., \& Allison, E. (2014). The role of mentalizing and epistemic trust in the therapeutic relationship. Psychotherapy, 51(3), 372-380.

Fonagy, P., \& Bateman, A. W. (2006). Mechanisms of change in mentalization-based treatment of BPD. Journal of Clinical Psychology, 62, 411-430.

Fonagy, P., \& Bateman, A. W. (2016). Adversity, attachment, and mentalizing. Comprehensive Psychiatry, 64, 59-66.

Fonagy, P., Gergely, G., \& Jurist, E. L. (Eds.). (2002). Affect regulation, mentalization and the development of the self. London: Routledge.

Fonagy, P., Gergely, G., \& Target, M. (2007). The parent-infant dyad and the construction of the subjective self. Journal of Child Psychology and Psychiatry, 48(3-4), 288-328.

Fonagy, P., Steele, M., Steele, H., Moran, G., \& Higgett, A. C. (1991). The capacity for understanding mental states: The reflective self in parent and child and its significance for security of attachment. Infant Mental Health Journal, 12, 201-218.

Fonagy, P., \& Target, M. (1996). Playing with reality: Theory of mind and the normal development of psychic reality. The International Journal of Psychoanalysis, 77, 217-233.

Gallese, V. (2007). Mirror neurons and the social nature of language: The neural exploitation hypothesis. Social Neuroscience, 3(34), 317-333.

Hesse, E., \& Main, M. (1999). Second-generation effects of unresolved trauma in non-maltreating parents: Dissociated, frightened and threatening parental behavior. Psychoanaytic Inquiry, 19(4), 481-540.

Main, M. (1996). Introduction to the special section on attachment and psychopathology 2: Overview of the field of attachment. Journal of Consulting and Clinical Psychology, 64(2), 237-243.

Malberg, N., Fonagy, P., \& Mayes, L. (2008). Contemporary psychoanalysis in a pediatric hemodyalisis unit development of a mentalization-based group intervention for adolescent patients with end stage renal disease. Annals of Psychoanalysis, 36, 101-114.

Midgley, N., Ensink, K., Lindqvist, K., Malberg, N., \& Muller, N. (2017). Mentalization-based treatment for children: A time-limited approach. Washington DC: American Psychological Association. 
Novick, K. K., \& Novick, J. (2005). Working with parents makes therapy work. Plymouth: Rowman \& Littlefield.

Rothbart, M. K., Sheese, B. E., Rueda, M. R., \& Posnes, M. I. (2011). Developing mechanisms of self-regulation in early life. Emotion Review, 3(2), 207-213.

Slade, A. (2008). Working with parents in child psychotherapy: Engaging the reflective function. In F. N. Busch (Ed.), Mentalization: Theoretical considerations, research findings and clinical implications (pp. 207-234). Mahwah, NJ: Analytic Press.

Slade, A. (2014). Imagining fear: Attachment, threat and psychic experience. Psychoanalytic Dialogues, 24, 253-266.

Sprang, G., \& Silman, M. (2013). Post-traumatic stress disorder in parents and youth after health-related disasters. Society for Disaster Medicine and Public Health, 7(1), 105-110.

Stricker, G., \& Gold, J. (1996). An assimilative model for psychodynamically oriented integrative psychotherapy. Clinical Psychology: Science and Practice, 3, 47-58.
Target, M. (2008). Commentary. In F. N. Busch (Ed.), Mentalization: Theoretical considerations, research findings and clinical implications (pp. 261-279). New York: Analytic Press.

Tessier, V. P., Normandin, L., Ensink, K., \& Fonagy, P. (2016). Fact or fiction? A longitudinal study of play and the development of reflective functioning. Bulletin of the Menninger Clinic, 80(1), 60-79.

Wang, G., Zhang, Y., Zhao, J., Zhang, J., \& Jiang, F. (2020). Mitigate the effects of home confinement on children during the COVID-19 outbreak. The Lancet, 395(10228), 945-947.

Publisher's Note Springer Nature remains neutral with regard to jurisdictional claims in published maps and institutional affiliations. 